\title{
Melatonin and Heart: A Tool for Effective Therapy in the Cardiovascular Disease?
}

\author{
Alberto Dominguez-Rodriguez ${ }^{1,2,3^{*}}$ \\ ${ }^{1}$ Complejo Hospitalario Universitario de Canarias, Department of Cardiology, Tenerife, Spain \\ ${ }^{2}$ Facultad de Ciencias de la Salud, Universidad Europea de Canarias; Tenerife, Spain \\ ${ }^{3}$ Instituto Universitario de Tecnologías Biomédicas. Tenerife, Spain
}

Melatonin or N-acetyl-5-methoxytryptamine is the hormone secreted mainly by the pineal gland that is under the control of the central nervous system via the suprachiasmatic nucleus of the hypothalamus. Because the pineal gland is active only in darkness, the levels of melatonin in the pineal gland and in blood are high at night and low during the day [1]. However, melatonin synthesis is not restricted to the pineal gland but it also takes place in megakaryocytes and platelets [2].

The discovery of melatonin as a direct free radical scavenger and as an indirect antioxidant via its stimulatory actions on antioxidative enzymes has greatly increased interest in the potential cardioprotective properties of this indoleamine. Several comprehensive reviews have summarized this topic in more detail [3,4].

Endogenous melatonin has shown to play an important role in the cardiovascular system [5]. Melatonin exerts its physiological functions through its chronobiotic, antiexcitatory, antioxidant, antiinflammatory, immuno-modulatory and vasomotor activities [6]. Indeed, the cardiovascular system is connected to the suprachiasmatic nucleus via multisynaptic autonomic neurons, and evidence confirmed that melatonin affects the cardiovascular system via these activities [6]. Moreover, melatonin receptors (MT1/MT2) have been identified in the heart and arteries [7]. Melatonin has been reported to influence blood pressure and heart function directly and/or indirectly by affecting cardiovascular risk factors including, amongst others, increased visceral fat accumulation and dyslipidaemia [4-6].

Several studies show that humans with cardiovascular disease have noticeably lower circulating melatonin levels than age-matched subjects without significant cardiovascular deterioration [4]. Brugger et al. [8] published the first clinical study in humans that demonstrated a relationship between melatonin and coronary artery disease. They reported reduced levels of plasma melatonin measured at 02:00 h in coronary artery disease patients. Moreover, other investigators studied nocturnal urinary excretion of 6-sulfatoxymelatonin, major melatonin metabolite, in patients with coronary artery disease and they demonstrated a low melatonin production rate [9-11]. Moreover, Yaprak et al. [12] demonstrated in patients with angiographically documented coronary artery disease, a decreased nocturnal melatonin synthesis and release. Similarly, patients suffering cardiac syndrome $\mathrm{X}$ have an attenuated nocturnal rise in serum melatonin levels related to that of age-matched individuals with no cardiac pathology [13]. Likewise, our group analyzed serum levels of melatonin and parameters of oxidative stress in a cohort of 25 patients with acute myocardial infarction and 25 subjects with no evidence of coronary artery disease as controls. We demonstrated that acute myocardial infarction is associated with a nocturnal serum melatonin deficit as well as increased oxidative stress [14]. Interestingly, a recent case-control study carried out by our group [15] showed a significant association between single nucleotide polymorphisms (rs28383653) of MT1A and coronary artery disease.

Melatonin is a small, highly lipophilic and hydrophilic molecule able to cross all morphological barriers and acts not only in every cell but also within every subcellular compartment. These pleiotropic activities have led to the suggestion that it may be used clinically in disease conditions where its circulating levels are reduced such as in cardiovascular diseases [4].

In conclusion, melatonin is an affordable, cheap and non-toxic molecule with exceptional potential to have a profound effect on public health.

\section{Funding}

This work was supported within the framework of one research project of the Spanish Society of Cardiology for Clinical Research in Cardiology 2012.

\section{References}

1. Reiter RJ (1991) Pineal melatonin: cell biology of its synthesis and of its physiological interactions. Endocr Rev 12: 151-180.

2. Dominguez-Rodriguez A, Abreu-Gonzalez P, Jimenez-Sosa A, Avanzas P, BosaOjeda F, et al. (2010) Usefulness of intraplatelet melatonin levels to predict angiographic no-reflow after primary percutaneous coronary intervention in patients with ST-segment elevation myocardial infarction. Am J Cardiol 106: 1540-1544.

3. Dominguez-Rodriguez A, Abreu-Gonzalez P, Reiter RJ (2012) Melatonin and cardiovascular disease: myth or reality? Rev Esp Cardiol 65: 215-218.

4. Dominguez-Rodriguez A, Abreu-Gonzalez P, Avanzas P (2012) The role of melatonin in acute myocardial infarction. Front Biosci 17: 2433-2441.

5. Dominguez-Rodriguez A, Abreu-Gonzalez P, Sanchez-Sanchez JJ, Kaski JC Reiter RJ (2010) Melatonin and circadian biology in human cardiovascular disease. J Pineal Res. 49: 14-22.

6. Dominguez-Rodriguez A, Abreu-Gonzalez P, Reiter RJ (2009) Clinical aspects of melatonin in the acute coronary syndrome. Curr Vasc Pharmacol 7: 367-373.

7. Ekmekcioglu C, Thalhammer T, Humpeler S, Mehrabi MR, Glogar HD, et al. (2003) The melatonin receptor subtype MT2 is present in the human cardiovascular system. J Pineal Res 35: 40-44.

8. Brugger P, Marktl W, Herold M (1995) Impaired nocturnal secretion of melatonin in coronary heart disease. Lancet 345: 1408.

9. Sakotnik A, Liebmann PM, Stoschitzky K, Lercher P, Schauenstein K, et al (1999) Decreased melatonin synthesis in patients with coronary artery disease. Eur Heart J 20: 1314-1317.

*Corresponding author: Alberto Dominguez-Rodriguez, Complejo Hospitalario Universitario de Canarias, Department of Cardiology, Ofra s/n La Cuesta E-38320, Tenerife, Spain, Tel: + 34922 679040; Fax: + 34922 678460; E-mail: adrvdg@hotmail.com

Received November 26, 2012; Accepted November 27, 2012; Published November 29, 2012

Citation: Rodriguez AD (2013) Melatonin and Heart: A Tool for Effective Therapy in the Cardiovascular Disease? Cardiol Pharmacol 2:e109. doi:10.4172/2329-6607.1000e109

Copyright: @ 2013 Rodriguez AD. This is an open-access article distributed under the terms of the Creative Commons Attribution License, which permits unrestricted use, distribution, and reproduction in any medium, provided the original author and source are credited. 
Citation: Rodriguez AD (2013) Melatonin and Heart: A Tool for Effective Therapy in the Cardiovascular Disease? Cardiol Pharmacol 2:e109. doi:10.4172/2329-6607.1000e109

Page 2 of 2

10. Girotti L, Lago M, lanovsky O, Carbajales J, Elizari MV, et al. (2000) Low urinary 6 -sulphatoxymelatonin levels in patients with coronary artery disease. J Pineal Res 29: 138-142.

11. Vijayasarathy K, Shanthi Naidu K, Sastry BK (2010) Melatonin metabolite 6-Sulfatoxymelatonin, $\mathrm{Cu} / \mathrm{Zn}$ superoxide dismutase, oxidized LDL and malondialdehyde in unstable angina. Int J Cardiol 144: 315-317.

12. Yaprak M, Altun A, Vardar A, Aktoz M, Ciftci S, et al. (2003) Decreased nocturnal synthesis of melatonin in patients with coronary artery disease. Int J Cardiol 89 : 103-107.
13. Altun A, Yaprak M, Aktoz M, Vardar A, Betul UA, et al. (2002) Impaired nocturnal synthesis of melatonin in patients with cardiac syndrome X. Neurosci Lett 327 143-145.

14. Dominguez-Rodríguez A, Abreu-Gonzalez P, Garcia MJ, Sanchez J, Marrero F, et al. (2002) Decreased nocturnal melatonin levels during acute myocardial infarction. J Pineal Res 33: 248-252.

15. Samimi-Fard S, Abreu-Gonzalez P, Dominguez-Rodriguez A, Jimenez-Sosa $A$ (2011) A case-control study of melatonin receptor type 1A polymorphism and acute myocardial infarction in a Spanish population. J Pineal Res 51: 400-404. 